\section{Standard XML Data Dictionaries for Chemistry}

A new project has begun under the Committee for Printed and Electronic Publications, entitled "Standard XML Data Dictionaries for Chemistry" (project \#2002022-1-024). It was developed in response to a widely accepted need for IUPAC to extend its leadership in the development of standard chemical terminology from printed to electronic communication, especially through the XML format. The principal objective of this program is to develop an effective means of enabling the use of IUPAC glossaries for creating a standard "namespace" for representing chemical information in digital form. This project seeks individuals interested in participating in any aspects of this task.

For more information, contact the Task Group Chairman Steve Stein <steve.stein@nist.gov>.

\section{www.iupac.org/projects/2002/2002-022-1-024.htm}

\section{IUPAC Chemical Nomenclature for Chemistry Teachers at Secondary Schools}

The Committee on Chemistry Education has initiated a new project to educate chemistry teachers at secondary schools and technical colleges in the Czech Republic about current IUPAC nomenclature of inorganic, organic, biochemical, and macromolecular compounds. The procedure could later be used as a model for replication in other countries.

Knowledge of current IUPAC chemical nomenclature among chemistry teachers at secondary schools and technical colleges in the Czech Republic is rather rudimentary. The faculties educating chemistry teachers do not seem to put sufficient stress on correct and modern chemical nomenclature. The situation is even worse with senior teachers as postgraduate studies in education are not available to them. There is no appropriate solution to the problem. The most important, current IUPAC-nomenclature documents are translated into Czech and published, but their treatment of the topics is difficult and too detailed for the teachers, explained Professor J. Kahovec, the task group chairman undertaking this project. Organizing postgraduate courses for secondary school chemistry teachers is a viable solution.

In the courses that the task group is planning, the fundamentals of current IUPAC nomenclature of inor- ganic, organic, and biochemical compounds, as well as that of polymers, would be outlined. The rules and the ideas behind them would be explained and illustrated in many examples. At the same time, the most frequent errors in naming would be demonstrated and corrected. A booklet containing a brief outline of nomenclature rules and, possibly, a final exam would form an important part of the course. Experienced nomenclaturists-preferably those taking part in translations of IUPAC documents-who are members of IUPAC or national nomenclature commissions, would give the lectures. The booklet and teaching materials initially prepared in Czech will subsequently be translated in English.

Preliminary inquiries among chemistry teachers showed great interest in such courses. As the number of chemistry teachers at secondary schools and technical colleges in the Czech Republic is quite high, several course offerings would have to be scheduled. A meeting is planned with the Department of Teaching and Didactics of Chemistry of the Faculty of Science of the Charles University in Prague to introduce this course on IUPAC chemical nomenclature into the curriculum for chemistry teachers.

For more information, contact the Task Group Chairman Jaroslav Kahovec <kah@imc.cas.cz〉.

\section{www.iupac.org/projects/2001/2001-016-1-050.html}

\section{Glossary of Terms Used in Photochemistry}

The "Glossary of Terms Used in Photochemistry," last published in 1996 (Pure and Applied Chemistry 1996, 68, 2223), included about 500 terms. Updating and expanding the glossary is needed since errors have been detected with respect to definitions in the IUPAC Green Book Quantities, Units, and Symbols in Physical Chemistry, published by the Physical Chemistry Division. In addition, terms related to the use of polarized light in photoinduced reactions should be included. By their very nature, glossaries need frequent updating to keep up with new terms and procedures arising from technological developments.

For more information, contact the Task Group Chairman Silvia E. Braslavsky<braslavskys@mpi-muelheim.de>.

(iii) www.iupac.org/projects/2002/2002-024-1-300.html 